

\section{Star Wars: The Force Awakens [the Western Pleasure Principle]}

\section{Alexander Rose}

At the time of this writing, Star Wars: The Force Awakens has broken the box office records for fastest film to $\$ 300$ million in domestic American sales and $\$ 610.1$ million worldwide (Mendelson 2015); the best Monday sales day at $\$ 40.1$ million, domestically; the best Tuesday sales day at $\$ 37.3$ million, domestically, and it ranks third on the all-time worldwide list at over \$2.1 billion (Box Office Mojo 2016). By any metric, the film is a force, if I might be forgiven the pun, in the film market. This of course means it is a force in the consumption space across product categories. By way of illustration, a search of online retail giant amazon.com for "Star Wars" yields 42,368 individual results in their "Toys and Games" category, 45,889 in "Home and Kitchen," and 47,452 in "Collectibles and Fine Arts."

What can this product, which is so successfully moving its own, as well as adjacent and tangential markets, tell us about those markets and the broader cultural context which constitutes them? That is, how can the text of a product inform our understanding of the social forces that structure its ascendancy and iconicity within that market? More practically, how can 
we use successful products and brands to 'reverse engineer' the ideological foundations which that product successfully addresses?

Marketplace mythology has long been acknowledged as a key component of consumer behavior and strategic efficacy (Crockett and Davis 2016; Holt 2002; Thompson 2004; Thompson and Tian 2008). Holt (2002, 2004) and Holt and Cameron (2010) make plain that iconic brands deploy myths to resolve cultural contradictions (Seregina and Schouten 2016). According to this view, brands serve as identity resources for consumers who draw on the mythic significations present in the brand's coded features. These resources are particularly potent when consumers find themselves faced with cultural contradictions. By cultural contradictions, theorists mean inconsistencies between cultural values and practices, such as the disparity between the 1980s ideal of the hard-working, blue collar American doing their part and the reality of automation, downsizing, and outsourcing in neoliberalization (Giesler and Veresiu 2014; Holt 2004; Holt and Cameron 2010).

Peñaloza $(2000,2001)$ showed how firms participate in the production and reproduction of myths that address cultural contradictions. Crockett and Davis (2016) recognized a gap in theorizing how such reproduction occurs; they provide a process for commercial mythmaking. 
This poses another interesting question: how can the myths be identified? How can the contradictions be identified? To understand a process, one must first identify ideologies, particularly contradictions between competing ideologies within a given market (Holt and Cameron 2010). This is a difficult task. Thompson and Tian (2008) use an extensive hermeneutic analysis. Similarly, though Thompson (2004) uses discourse analysis, many firms may not have the human capital or economic capital resources to conduct such a study. Crockett and Davis (2016) go larger still, conducting a thorough ethnography of a religious theme park in the US. For some firms, large-scale ethnography is often out of the question for budgetary or practical reasons, like a lack of institutional support for the method. So how then can managers looking to deploy cultural strategies and build iconic brands that cut across product categories, like Star Wars, identify relevant ideological opportunities in their target market?

I propose the use of psychoanalysis of the collective. While psychoanalysis has played a key role in the development of consumer research (Tadajewski 2006), to my knowledge the analysis of a collective has not been explicitly used in the literature. Oswald (2010) employs psychoanalytic methods, but focuses on the individual consumer's mindset. Shortly thereafter, Cluley and Desmond (2015) organized a special issue in Marketing Theory about 
psychoanalysis and its uses for marketing today, but the focus remained on the individual. Reyes, Dholakia and Bonoff (2015) underscore that the Lacanian psychoanalytic concept of lack of being underwrites the pleasure of consumption for individuals, which is translatable to collective issues in consumer culture. Jung justifies studying the collective as a unity in order to deduce understandings of the collective unconscious (Jung and Von Franz 1968). Žižek has acknowledged this call and frequently draws on psychoanalytic methods in analyzing broad cultural contexts and trends (e.g. 2009). Rather than identifying personality patterns, one is identifying ideological patterns. Since ideology operates largely outside of conscious thought (Althusser 2006; Marx and Engels 1970), this is consistent with the concept of the subconscious on an individual level.

In sum, then, the aim of the present manuscript is to show how psychoanalytic methods can be used to analyze a target market's ideological context and identify potential contradictions that can then be addressed with an iconic brand. This is accomplished through the 'reverse engineering' of an iconic franchise's product. There are several contributions. The primary one is to offer a tool to help those interested in utilizing cultural strategy identify ideological opportunities in a given target market when ethnography is out of the question. Secondarily, I show how lessons can be gleaned from a successful product's ideological appeal. Those 
interested in mimicking the success of the Star Wars franchise would be well served to consider these. Third, while much discussion has revolved around the role of myths in marketplace successes (e.g. Holt 2004; Giesler 2008; Holt 2004; Cameron and Holt 2010; Peñaloza 2000, 2001; Thompson 2004; Thompson and Tian 2008), only Crockett and Davis (2016) has examined an explicitly mythical product. That is, while Thompson (2004) for instance examines the organic food market, organic food is not itself an explicitly mythical text; Star Wars, however, is a narrative the mythical core of which is well-recognizable to its target market. These explicitly mythical products are particularly potent for analysis as they are directly revelatory of the context in which they succeed or fail. Moreover, we know that persuasion is more effective through narrative than control (Miles 2015), so examining an explicitly, or perhaps functionally, mythic text will be informative.

In terms of a roadmap, I will begin by analyzing the Star Wars text as a dream-image in psychoanalysis. Drawing on the text of Star Wars: The Force Awakens, I identify three key tensions and analyze them. This process reveals the tensions between competing meanings that are hidden in the movie. From there, I expand those tensions to the broader ideological context through the lens of Freud's pleasure principle and the process of inversion. In this way, the contradictions point to the ideological context. The manuscript concludes by discussing the 
ramifications of these analyses for firms wishing to utilize the cultural strategy models; for understanding the success of Star Wars and what it says about the target market which enjoys it; and for broader academic discussions of marketing and consumer behavior.

\section{Psychoanalysis}

Psychoanalysis has always been inherently clinical; this fact has often been overlooked in criticisms of the concepts and method (O'Shaughnessy 2015). The task is to comprehend mental meanings and then offer a solution to overcome issues presented thereby (Freud 2013). While the task of the marketer who seeks to employ it to analyze a collective is not clinical per se, she is nonetheless tasked similarly with comprehending ideological conflicts and contradictions within the collective 'subject'. In the former case, a psychoanalyst might observe a behavior, search for meaning within it, and then offer a solution. Similarly, in this case, we analyze something we know to be liked - a successful product — and use its peculiar aspects as indicators in an effort to characterize the market that has chosen it. In other words, if Holt (2004) is right, then successful products will be those that address ideological contradictions. Working backwards, we can see which contradictions successful products 
serve, thereby reverse engineering the ideological foundations which motivate consumption of the product in question. With this information in hand, we can then make value propositions that are not built on mimicking the success of the analyzed product, but that are instead directed towards the same collective machinations that led to use said product as an identity resource, as they do in iconic brands (Holt 2004).

In doing this, I sought out basic principles of psychoanalysis. This is an interpretive process (Tadajewski 2006), so there is no decision tree or similar heuristic. Instead, the marketer-asanalyst must hone their insights into the market in question in order to develop sufficient fluency to be comfortable reaching a conclusion. As mentioned earlier, the idea here is to equip those interested in macro-collective analysis with a tool that can be used in lieu of more expensive and personnel-intensive analyses like ethnography or surveys. Critically, this maintains space for creativity and insight. Nevertheless, in the interest of providing a starting point for those without exposure to psychoanalytic principles, I have included a table of what I consider to be eight useful principles for analysis.

Before employing these tools, however, one must have something to analyze. In a therapy session with a dream as the object of analysis, the clinician and the patient would go through 
the dream bit by bit to look for themes. These themes act as cues to inform the analysis. The underlying unconscious neurosis will manifest in the themes. Our purpose is similar, so thus too must be our task. Instead of a dream, we will be looking at the text of a Star Wars film.

\section{Identification of Themes}

For the sake of scope, I limit the text for my analysis to the latest installment in the Star Wars franchise at the time of this writing. While I considered expanding it to include all eight films, the trailer for the upcoming film, and the various canonical works of written fiction in order to justify claims of comprehensiveness, I do not believe it would meaningfully affect the interpretation while adding considerable material to be discussed in the analysis; the benefit is too dubious to warrant the expansion of scope for the present endeavor. Further and practically speaking, the expectation that every text relevant to the analysis should be included would substantially increase the burden on others wishing to use this technique. Of course, with an analysis of the content of the text comes a necessary disclosure of information about the film itself. Thus, with apologies to Yoda, cautioned, you've been; spoilers, there are. Proceed with 
caution. What follows is a reading of the text for themes, particularly ones that stand out as related to potential tensions.

\section{The Force}

The first theme is titular; the Force is a central concept both to the film and to the franchise.

Imminently recognizable to its fans, 'the Force' is the principle component of the world of Star

Wars. In essence, the Force is a dualistic concept wherein light and dark, good and evil, are in competition rather than balance, but are closely connected. As character Maz Kanata puts it, "It moves through and surrounds every living thing. Close your eyes. Feel it. The Light. It has always been there. It will guide you." Consistent with this and pervading the storyline is this notion of walking the "good" path of the light side of the Force. This entails self-control, mastery of one's emotions, and a dedication to the service of others. Indeed, in the opening scene of the film, San Tekka suggests that the Dark Side and truth itself are incompatible. In other words, the light side is not only just, but the sole path to facticity.

The Dark Side is the inverse. It is the antithesis of goodness and self-sacrifice. It is inherently selfish and driven by the passions. It is the enemy of the light to such an extent that Kanata 
says, when questioned about the importance of the fight, "The only fight: against the Dark Side. Through the ages, I've seen evil take many forms: The Sith; the Empire; today, it is the First Order. Their shadow is spreading across the galaxy. We must face them, fight them, all of us." Their diametric opposition is emphatically stated.

Affiliation with either side of the Force grants powers to its users. Those who use them are categorically connected with the political structure of the film, a point to which we shall return momentarily. For now, though, consider the extent to which the Light Side grants powers that, out of context vis-à-vis the Dark Side, would seem heinous. For instance, when the principle visible villain of the film, Kylo Ren, interrogates people, he does so through brute force. His interrogation is mental and silent, but appears to be a cracking open of resistance. When dealing with Poe Dameron, he inflicts pain until Dameron gives him the information he seeks. When dealing with Rey, the principle protagonist, he similarly engages in the infliction of pain. The answers he receives appear to be a function of misery and voluntary cessation thereof; agency is retained by the interrogated. This is supported further by Rey's ability to resist him. She simply declines to reveal the information to him, they have a silent confrontation of powers, and he fails, to his chagrin. All this interrogation seems, on its face, evil enough. 
But consider Rey's first major act of power. Voluntarily, she uses the Force, the Light Side, the goodness, the righteous path, to commit an act that is singularly vile and yet completely unquestioned in the film. After successfully navigating her interrogation, an anonymous goon of a villain (who is in fact played by Daniel Craig in a cameo), a storm trooper, visits Rey. The fact that these goons are named after specialty combat units for the German Empire is not accidental; I will return to the point shortly. Rey's act upon this storm trooper is to tell him, shakily, that he "will remove these restraints and leave the cell with the door open." At first, he refuses and insults her. She says it again, with confidence, and he does just that. This is an ability granted by the Force, somewhat akin to the power of suggestion.

But what is it really? Rey has stolen the agency of this storm trooper. Can there be a more fundamentally unethical act? Is there anything viler to the bourgeois concept of the individual than the subversion of the will? Perhaps, one wonders, this is justified by good's need to fight evil. This is a storm trooper. As Finn says, he - and presumably the trooper Rey manipulateswas "taken from a family [he'1l] never know and raised to do one thing." Is this really an evil being? Has he not himself been subverted already? Finn reveals further that not all storm troopers are evil manifestations of the Dark Side when he quits; he is frightened by the task of doing evil despite years of indoctrination. Is Finn the sole outlier? Are we to blame the victim 
of abduction and indoctrination for his deeds? And if so, to what extent? Can we justify the further manipulation of his self-determination for the sole purpose of helping her escape custody? Again, these questions provoke shadows of the next two binaries to be discussed: the categorical affiliation of Force users (Jedi/First Order) and the political structure of the galaxy.

The inconsistency of the Light Side doesn't stop here. Earlier in the film, Rey chooses to help an artificial intelligence — a 'droid'—named BB8 in the pursuit of its previous owner, the aforementioned Poe Dameron. She forgoes a hefty bribe offered to her to surrender the droid, she actively prevents the droid from being abducted, and she chooses to abandon her yearslong wait for her parent(s) to help him find Dameron. Like the inverse of the aforementioned Dark Side activities, this Light Side behavior seems good enough. But this is not necessarily so. Consider for a moment the dynamic belied by her language in relation to the droid. Despite acknowledging BB8's personhood by admonishing a scavenger that has "no respect for anyone," Rey consistently refers to the droid's erstwhile companion as his "Master." When she and BB8 see Finn wearing Dameron's jacket, she says “it belongs to his Master.”

Thus, a machine that deserves respect for its personhood, that can't be pawned off for petty bribes like food, and that is indeed named and given pronouns, is effectively labeled a slave. 
The dynamic of cooperation apparent in the interaction between droids and humanoids is belied by the explicit conceptualization of the relationship as one of master/slave. How are we to reconcile this with the wholesome image of the Light painted by Kanata above?

Simple. The binary is preposterous. It explodes under scrutiny. The Dark Side is the path of emotion. But any concept of the sentient life absent affect is worthy of criticism. The Light Side is the path of warmth and guidance, but its adherents enslave sentient machines. The Dark Side has its underlings limited in their interrogation abilities, while the Light Side allows for the outright subversion of agency. The Light and the Dark are complex, interrelated, and difficult to process. But the binary is central to the film. In fact, its centrality cannot be overstated. It is titular. It is essential to the plot. It is foundational to the characters. Before analyzing the extent to which we can glean anything from the prominence of this shaky binary in this wildly popular text, let us consider two other themes. As alluded to above, this includes the practitioners of the Force and the political structure.

The Jedi and Their Opposition 
In the beginning of the film, there is a 'crawl,' or written introduction to the context of the story. Here, the first evidence of our second major theme is presented. The crawl reveals that the villains of the film, the First Order, "will not rest until Skywalker, the last Jedi, has been destroyed." The Jedi are an order of Light Side Force users. They are para-political; their power is used in support of the Republic, but not explicitly as part of it. In The Force Awakens, they are utterly absent, as revealed by the crawl quote. Only one Jedi remains and he is in hiding. But their importance is still central to the film, and thus so too is their relationship to the villainous Force users.

In previous films, the Dark Side users, the Jedi's opposition, were known as Sith. In this film, there is no explicit Sith character. Instead, the Dark Side users are not given a formal title. They include Supreme Leader Snoke, who appears to be the mastermind of the villains. He trained the key opposition figure, Kylo Ren, and Ren and Hux both report to him directly with matters of the First Order's concern. Indeed, Leia Organa reveals in a conversation with Han Solo about Ren, their son, that Snoke is the ultimate villain when she says that, "It was Snoke. He seduced our son to the Dark Side.” 
This remark is noteworthy for our present purposes as it shows the way in which the canonical elements of the story handle the Dark Side and Light Side practitioners. The Jedi and their supporters speak often of seduction by and to the Dark Side. She seems to suggest that, like some Dark Side magnet, Snoke drew in and then hoodwinked their son. But she immediately follows this comment up by saying, "we can still save him," with regards to Ren. Can the same not be true of Snoke? Let us not forget, too, that the film begins with Kylo Ren overseeing and participating in the slaughter of an entire village of innocent people. If there is goodness in him despite these actions, surely there must be goodness in everyone.

This duality is further complicated by Ren's own words to Snoke. He says, while genuflecting, "By the grace of your training, I will not be seduced." Here he seems to be implying that he must rise above temptation towards the Light Side. But if the roles are clearly good and evil, control and abandon, reason and emotion, then surely the masters of the latter's practice would recognize it as such. How can one be 'seduced' by goodness, control, or calm? And if, as Ren suggests to Rey while he is interrogating her, he knows the power of the Dark Side, why should he be 'seduced' by what he left behind in deciding to join it?

Perhaps the most damning element is revealed by a line early in the film. Lor San Tekka, who is shortly thereafter executed by Ren, says, "Without the Jedi, there can be no balance to the 
Force.” This appears to be a statement of yin/yang duality (Fang 2012), wherein Light Side practitioners must exist alongside Dark Side practitioners. But a closer look reveals that this isn't so. While the Dark Side users certainly seem bent on destroying the Light Side users, the same is also true. How can an organization that is built to eradicate its opposition be reliably called a balancing agent? Moreover, how can those who admonish others over the need for balance fail to see the necessity of their opposition? Light is only meaningful with respect to Dark and vice-versa, yet each actively seeks to eradicate the other. Only the Light pays lip service to the idea of balance in the process.

The failure of this duality is illustrated quite simply by Ren in a bit of repartee with Rey. She asks, nay demands, "Where are the others?!" and he replies calmly, "You mean the murderers, traitors, and thieves you call friends?" Both the Light Side practitioners and the Dark Side practitioners act contrary to their stated views, often nearly simultaneously. Light Side users seek to eradicate Dark Side users in the name of Balance, while Dark Side users claim to understand the ways of the Force better than anyone while speaking candidly about their fears of seduction to the Light. In Ren's pity commentary, he names her friends murderers - as a practitioner of the Dark Side, would this not then render them his friends? The glossed-over inconsistency is essential to the film's success, I argue. Indeed, I maintain that the refusal of the 
film to reconcile the mismatch between deeds and words is highly revelatory of the market which devours it. Before further analysis, though, I turn to the last of the three principle themes and the one that may be the most explicitly revealing of the character of its viewing audience.

Politics: the Resistance and the Republic, the First Order and the Empire

The political structure of the Force Awakens film is starkly divided. At every turn, the viewer of the film is shown the extent to which the First Order, the villains, are truly villainous. The extreme is noteworthy. As mentioned previously, they are run by practitioners of the Dark Side of the Force. While they are not explicitly labeled Sith, these leaders are nevertheless shown to be hateful, torturous, and capable of extreme acts of violence, including the wholesale slaughter of innocents on a planetary scale.

Perhaps the most telling scene is a speech given by General Hux prior to the use of their powerful weapon of mass destruction. One cannot help but be struck by the degree to which the First Order gathered resemble assembled fascists. They wear black with red touches, reminiscent of the Third Reich. For that matter, the ordered - no pun intended, though the connection is telling - and organized nomenclature seems a direct tip-of-the-hat to Nazis. Like 
every good fascist, they abhor disorder. Hux screams, preaching to an assembled mass with billowing red banners at his back, that as they destroy the Republican Capitol of Coruscant, "Today is the end of the Republic — the end of a regime that acquiesces to disorder, secretly supporting the treachery of the loathsome resistance." He concludes his frothy-mouthed tirade with a raised hand; the assembled crowd returns it with a snappy and familiar one-armed salute. But this fevered spiel reveals a critical failure of the presentation of the two political structures. This issue is foreshadowed in the crawl: the "sinister FIRST ORDER has risen from the ashes of the Empire... with support of the REPUBLIC, General Leia Organa leads a brave RESISTANCE." How peculiar that the established government backs a resistance. To what? How can the hegemony be simultaneously the resistant? Indeed, how is it that the First Order rose from said ashes in the first place if the Republic reigned? The crawl intimates that the Resistance seeks to gain Luke Skywalker's "help in restoring peace and justice to the galaxy." Where did it go? Why wasn't it stopped before it became capable of destroying a planet?

In other words, the film presents the protagonists as scrappy underdogs, despite the fact that they are the hegemonic power of the system. Moreover, they present the villains as allpowerful, highly organized rallying fascists set to bring the engines of war to the brave but 
outclassed heroes. But simple logic breaks this down. How is it that the First Order were able to become an order at all? How did they acquire the means to create weapons of such destruction? How did they build a fleet? C3PO despairs, "Without the Republic fleet, we're doomed." Hux concurs: "Without their friends to protect them, the Resistance will be vulnerable." If the Republic holds a fleet and possesses sufficient power to protect the Resistance, why is there the need for a Resistance at all? Why wouldn't this fleet simply eradicate said order before it can reach its planet-destroying zenith? And how do the Resistance get labeled treacherous? Isn't the First Order the traitorous organization of fascist usurpers, defying the democratic government?

The icing on the cake of this theme is found atop the head of the leader of the Resistance. Leia, who holds a Generalship and leads these brave freedom fighters in their resistance against a fascist sub-state that has arisen without issue from the established state, is hardly a Republican figure. San Tekka gives the game away early in the film when he says, "General? To me, she's Royalty." This is a reference to Leia's background as an adopted princess of Alderaan. Royal bloodlines are fighting a Resistance to an apparently permitted, or at least tolerated, sub-state? This hardly smacks of radical democracy. The Resistance appears to have a threefold mission: to restore the Jedi, to maintain balance, and promote... something, presumably ideal and good. 
What, exactly, is unclear, aside from resistance to the First Order. If that were successful, what is the end-game? The establishment of a Republic? But it exists! I assume the Senate would be startled to learn that there is a new Republic in town. This is said to be done "on behalf of the Republic," but if the Republic has a fleet that could protect the Resistance, that is, one with enough capability to defeat the First Order, then why does the Resistance need to act on their behalf in the first place?

All told, the tension that the film sets up between the truly heinous First Order and the Bad News Bears Resistance falls apart under scrutiny, just as the Light Side and Dark Side and the Jedi vs Sith or Order of Ren do. The thrust of this essay, though, is not to show that these dualisms fail, but rather to explore the extent to which those themes and their rather obvious failures can be used to draw important conclusions about the collective unconscious of the viewing audience, particularly in the absence of large-scale ethnography or as an alternative to survey methods. To that end, I turn next to the task of analyzing the collective viewership of the film in light of its success with these shaky binaries.

\section{Analysis}


With these themes pulled from the text, we can now begin the true task: analyzing the artifact for insight into the collective unconscious. This requires the use of some orienting concept. I drew from the list I provided in table 1 to use what is perhaps the most recognizable concept from psychoanalysis: the pleasure principle (Freud 2013). While Freud himself later acknowledged that it was not the exclusive motivating force in human consciousness, even his harsh critics acknowledge that it is an important one (Jung and von Franz 1968; O'Shaughnessy 2015). In essence, the pleasure principle is that the mind seeks pleasure and avoids pain for psychological purposes. Taken at the macro level, then, it suggests that, as we might expect, Star Wars is so successful because it makes its audience feel good and avoid feeling bad.

An obvious objection here emerges. What of the fact that so much of the imagery and concepts in Star Wars, as we have just seen, are contradictory and at times outright disturbing? How are we to reconcile our identification of these thematic tensions and their rather flimsy dualisms that lie at the heart of the product and its brand narrative with the notion that its audience enjoys it so thoroughly? Here, too, Freud provides a tool. In particular, he offers a concept that is one of his foundational methods for analyzing dream images: inversion. Inversion is, 
according to Freud, the mind's transformation of one thing into its opposite in order to disguise it. Thus, here then is our answer.

It is my contention that the success of the Star Wars franchise has not occurred despite its apparent inconsistencies of meaning, but rather because of them. Specifically, one sees that the market which has devoured it—specifically though not entirely limited to American and Western markets - seeks pleasure in images that it subconsciously realizes to be an inversion of reality. Consider the political structure described in the text. American moviegoers have shown that they love to identify with the scrappy upstart Resistance and love with equal fervor to scorn the First Order's fascist overtures. But this is of course despite the fact that on a geopolitical level, the US is the hegemonic force of global violent imposition. Star Wars fans can thus go watch The Force Awakens and cheer as menacing spaceships float across the screen, terrifying the good (albeit poor) people around them before returning home to watch the nightly news and see menacing battleships float across the television screen, terrifying the evil (albeit poor) people around them.

There is a term for this, and likely a familiar one: a defense mechanism. This is a particular kind of reaction formation (Freud 2013), a mental tendency that emerges to protect the mind's 
beliefs about itself. In this case, the market for the film is so enthusiastic because it serves to reinforce a myth popularized within that market. While resistance, revolution, esprit de corps, and the goodness of humanity is celebrated in Western ideals, the dirty work of economic (and sometimes more direct) imperialism is a painful threat to one's mental comfort. Indeed, it offers powerful symbolic evidence that the ideals thrive; viewers are, after all, rooting for the Resistance. That only a handful of countries on Earth possess a weapon of relatively-equivalent power to Starkiller Base of the First Order is happily sublimated into the imagery of Light vs Dark.

Thus, Star Wars appeals to the affinity Western culture has for its ideals as contrasted sharply with its less glamorous realities. Particularly within the US, the market for the film is colossal as it plays the role of a commercial myth (Crockett and Davis 2016; Thompson and Tian 2008), disseminating and protecting ideology for its viewers. Recall the foundational lesson of the cultural marketing strategy: identification of contradictions and the supplying of identity salves to protect individuals caught up within those contradictions (Holt 2004; Holt and Cameron 2010). This, then, is the lesson: these contradictions can be identified and understood via psychoanalytic concepts. In this particular instance, the contradictions are political and ethical. The market's cultural context is one of a belief in independence and behavior of domination, 
paired with a strong ethical value for spirituality and insight but policies that are often ominous and domineering. This creates a contradiction that, according to the cultural strategy model, creates an opportunity. Brands that provide consumers with the means to address that contradiction can achieve iconicity.

\section{Implications}

The analysis is only useful insofar as it can illuminate insights into the market in question for other products; clearly Disney needs no help accepting the value propositions associated with Star Wars, as they must have concluded before paying $\$ 4.05 \mathrm{bn}$ for the rights. So what then can we conclude from the exercise? I organize these implications by category, beginning with the relevant conclusions for cultural strategy.

\section{Cultural Strategy}

First, we see that the contradiction between Western political values and actions is a considerable one, and that its severity makes it ideal for resolution through brand value 
propositions. As Holt (2004) suggests, when a firm can supply these identity salves in the face of cultural contradictions, their brands can reach iconic status. Star Wars is no exception as it shows a coherent story wherein the heroes contradict themselves with respect to their opposition to the villains, just as an American audience must contend with its belief in the power of individual determination and the political tendency to intervene in the selfdetermination of others (e.g. Chomsky 2007; Klein 2007).

Second, and flowing from the first, is the point that the contradictions that are so potent for the Star Wars franchise are fecund enough to be tapped into by other market offerings. Contradictions between and within values, politics, and ethics are broad-scale social issues. As such, the ability to provide resources to face them cannot be fully actualized by a single product. As such, other firms should consider this contradiction when formulating their cultural strategies. From consumer packaged goods to access-based services (e.g. Bardhi and Eckhardt 2012; Lamberton and Rose 2012), providing American consumers with narratives that can ease the tension between their collective ideals and collective actions opens up the possibility of building an iconic brand. Managers would be well served to consider how and to what extent their value propositions can potentially address these tensions in a meaningful way, even if that way is to sublimate them into one another. 
This leads to the third point and perhaps the most important: that the contradictions need not be resolved by the product or brand in order to be addressed by them. Holt (2004) and Holt and Cameron (2010) offer several case studies to support their strategic model, but they show how the firms in question have resolved the ideological contradiction through their product and/or brand. My context, on the other hand, shows that a functional response to these contradictions can itself be a contradiction. Indeed, few product franchises have the brand price tag that Star Wars carries; arguing its value would be futile. Thus, one must concede that, in a manner quite consistent with psychoanalytic theory, the collective unconscious can latch onto inverted imagery and meanings.

Fourth and finally, those interested in developing cultural strategies for brandsmanagers, consultants, small business owners, and so on—can now consider a cost-effective alternative to extensive fieldwork or survey protocols. While there is no substitute for experience, I contend that one may use psychoanalytic concepts to probe the collective unconscious of markets. In building a cultural strategy, one must identify contradictions and seek to address them, even obliquely as we have seen, through one's products, services, and brand. Identifying these contradictions is a tall task when human or economic capital may be limited. A survey may also not effectively identify these contradictions as self-report is likely 
to fail to detect the sublimated and contradictory meanings revealed by preference or behavior.

Working backwards, one may find issues that are resolved by existing, successful products and then orient one's strategy towards those. In a related vein, one may consider other 'telltale' signs like political decisions, public events, and so on as indicators for one's analysis.

\section{Academic Literature}

What of the implications for the academic literature? First, we have learned that ideological value can be offered in indirect ways: much of the benefit to Star Wars lies in its apparent simplicity and its contradictions to the structure of the market. Where one might assume that a global hegemony would prefer products that echo its status in the world, it is more important that the products echo its myths (Crockett and Davis 2016). Indeed, it may very well be preferable that the product avoid the reality of the matter, with good reason.

Second and importantly, inconsistencies in the product, its narrative content, or its brand narrative is no threat to its success. Indeed, a fundamental lesson of many Integrated Marketing Communications courses is that consistency and synergy between signs is essential to effective conveyance of value offerings. But clearly this is not the case. As demonstrated, the 
foundational significations of the Star Wars product and brand are haphazard, inconsistent, contradictory, and as stated, quite at odds with the reality of its target market. Nonetheless, it sits happily atop revenue charts.

Seeing defense mechanisms surrounding the happy consumption of a myth in which the good guys are relatable yet dissimilar to the consumer and the bad guys are villainous yet highly similar raises an interesting connection to the work of Chatzidakis (2015). He theorizes that, based on the concept of unconscious guilt as a motivating force, it is not self-regulation that emerges as a consequence of bad behavior but rather the opposite. In other words, the internalization of an authority figure leads to defiance of those internalized rules, rather than the traditional view of deviance prompting regret and intentions to self-regulate. For our purposes, this is instructive in the sense that it helps illuminate the mechanism underlying the American market's preference for the Resistance over the First Order. This is the third lesson. By internalizing the authority to police the globe and maintain order on behalf of American (and presumably allied) interests, Americans also create a motive to act against that. Thus, they cheer for the upstart rebels to destroy the unimaginably expensive weaponry, knowing that they must 'know better' than to side with the terrorists against order. Even the nomenclature of the two organizations feeds into this idea: subconscious authority (i.e. the superego [Chatzidakis 
2015]) provides order while actions resist (note puns) it. After all, consumers are encouraged to embrace desires and abandon rationality (Schwarzkopf 2015); deviance is a natural desire.

In sum, then, we see that the process of cultural strategy and mythmaking identified by Holt (2004) and Crockett and Davis (2016) begins with the identification of myths. Psychoanalysis is a useful tool in that process, especially from a practical cost/benefit perspective. The value that is distilled from these mythical offerings may be indirect and contradictory and yet effective. Indeed, we might believe that it is the inconsistency which motivates the consumption; there is a deep pleasure in acting against one's better nature. But I would be ethically remiss if I did not close with a warning from Yoda: “...beware. Anger, fear, aggression. The dark side are they. Once you start down the dark path, forever will it dominate your destiny."

\section{Limitations}

It is worth admitting explicitly that the idea of launching psychoanalysis as a desk-drawer tool for managers is complicated. I intentionally have presented an accessible version here with the genuine intention of answering the question, "The cultural branding model sounds great, 
but how do I do it?" that I hear so often in my MBA classes. I developed this technique to answer that question and I use it in the classroom to good effect, amongst both full-time and professional MBAs, the latter of which is compromised almost exclusively by seasoned managers.

That being said, it would take a systemic effort to begin to train business school graduates to use psychoanalysis in the marketing careers. I would advocate for this and intend to do so. But it is a barrier and a challenging one. Still, psychoanalysis has enjoyed a rather prominent role in marketing traditionally (O'Shaughnessy 2015), even when only tangentially acknowledged as in the work of Bruce Barton (Lears 2000). Perhaps its renaissance would not be met with as much resistance as I anticipate.

This is not to equivocate too much on the admission, though. Psychoanalysis is an immense field with a long history, good and bad. It is a clinical tool. It is the subject of a nearly endless series of jokes about cigars or mothers. The task isn't an inconsequential one, but I believe the technique would be a useful, explicit addition to the marketing repertoire. May the force be with you. Always.

\section{References}


Althusser L (2006) Ideology and Ideological State Apparatuses (Notes Towards an Investigation) The Anthropology of the State: A Reader 9(1), pp. 86-98.

Bardhi F and Eckhardt GM (2012) Access-based Consumption: The Case of Car Sharing. Journal of Consumer Research 39(4): 881-898.

Chatzidakis A (2015) Guilt and Ethical Choice in Consumption: A Psychoanalytic Perspective. Marketing Theory 15(1): 79-93.

Chomsky N (2007) Failed States: The Abuse of Power and the Assault on Democracy. New York: Metropolitan Books.

Cluley R and Desmond J (2015) Why Psychoanalysis Now? Marketing Theory 15 (1): 3-8.

Crockett D and Davis L (2016) Commercial Mythmaking at the Holy Land Experience. Consumption Markets \& Culture 19(2): pp. 206-227.

Fang T (2012) Yin Yang: A New Perspective on Culture. Management and Organization Review 8(1): 25-50.

Freud S (2013) The Interpretation of Dreams. Worcestershire: Read Books.

Giesler M (2008) Conflict and Compromise: Drama in Marketplace Evolution. Journal of Consumer Research 34(6): 739-753.

Giesler M and Veresiu E (2014) Creating the Responsible Consumer: Moralistic Governance Regimes and Consumer Subjectivity. Journal of Consumer Research, 41 (3): 840-857.

Holt DB (2002) Why Do Brands Cause Trouble? A Dialectical Theory of Consumer Culture and Branding. Journal of Consumer Research, 29 (1): 70-90.

Holt DB (2004) How Brands Become Icons: The Principles of Cultural Branding. Cambridge: Harvard Business Press.

Holt D and Cameron D (2010) Cultural Strategy: Using Innovative Ideologies to Build Breakthrough Brands. Oxford: Oxford University Press.

Jung CG and Von FM. (1968) Man and His Symbols. New York: Laurel. 
Klein N (2007) The Shock Doctrine: The Rise of Disaster Capitalism. Basingstoke: Macmillan.

Lamberton CP and Rose RL (2012) When is Ours Better than Mine? A Framework for Understanding and Altering Participation in Commercial Sharing Systems. Journal of Marketing 76(4): 109-125.

Lears TJ (2000) From Salvation to Self-realization: Advertising and the Therapeutic Roots of the Consumer Culture, 1880-1930. Advertising \& Society Review 1(1).

Marx K and Engels F (1970) The German Ideology (Vol. 1). New York: International Publishers Co.

Mendelson S (2015) 'Star Wars: The Force Awakens' Box Office: Record \$40M Monday, \$610M Worldwide'. Available at: https:/www.forbes.com/sites/scottmendelson/2015/12/22/star-wars-the-force-awakens-boxoffice-40-1m-monday-610m-worldwide/\#186bc2e24838

Miles C (2015) Ericksonian therapy as a grounding for a theory of persuasive marketing dialogue. Marketing Theory 15(1): 95-111.

O'Shaughnessy J (2015) Note on the marginalizing of psychoanalysis in marketing. Marketing Theory 15(1): 17-19.

Oswald LR (2010) Marketing hedonics: Toward a psychoanalysis of advertising response. Journal of Marketing Communications 16(3): 107-131.

Peñaloza L (2000) The commodification of the American West: Marketers' production of cultural meanings at the trade show. Journal of Marketing 64(4): 82-109.

Peñaloza L (2001) Consuming the American West: Animating cultural meaning and memory at a stock show and rodeo. Journal of consumer research 28(3): 369-398.

Reyes I, Nikhilesh D and Jennifer BK (2015) Disconnected/connected: On the "look" and the "gaze" of cell phones. Marketing Theory 15(1): 113-127.

Schwarzkopf S (2015) Mobilizing the depths of the market: Motivation research and the making of the disembedded consumer. Marketing Theory 15(1): 39-57. 
Seregina A, and Schouten JW (2016) Resolving identity ambiguity through transcending fandom. Consumption Markets \& Culture 20(2): 1-24.

Tadajewski M (2006) Remembering motivation research: toward an alternative genealogy of interpretive consumer research. Marketing Theory 6 (4): 429-466.

Thompson CJ (2004) Marketplace mythology and discourses of power. Journal of consumer research 31 (1): 162-180.

Thompson C and Kelly T (2008) Reconstructing the south: how commercial myths compete for identity value through the ideological shaping of popular memories and counter memories. Journal of Consumer Research 34 (5): 595-613.

Žižek S (2009). First as tragedy, then as farce. Verso. 